\title{
Deletions in the $17 q$ chromosomal region and their influence on the clonal cytogenetic evolution of recurrent meningiomas
}

\author{
Sina Hemmer, Steffi Urbschat, Joachim Oertel and Ralf Ketter ${ }^{*}$ (i)
}

\begin{abstract}
Objective: Meningiomas are among the most frequent intracranial tumors. Although the majority of meningiomas can be cured by surgical resection, up to $20 \%$ of the patients develop an aggressive clinical course with tumor recurrence or progressive disease.

Cytogenetically, meningiomas frequently harbour a normal karyotype or monosomy of chromosome 22 as the sole anomaly. However, progression of meningiomas is associated with a non-random pattern of secondary losses of the chromosomes and chromosomal regions 1p, 6, 10,14, 18, and 19. There is evidence, that loss of chromosome 17 might be involved in the clonal cytogenetic evolution of recurrent meningiomas. The aim of this study was to determine the role of deletions in the $17 \mathrm{q}$ chromosomal region in patients with recurrent meningiomas.
\end{abstract}

Results: The authors retrospectively reviewed all patients that underwent repeated surgery for recurrent meningiomas between 1999 and 2015 at the Department of Neurosurgery of the Saarland University Hospital. Patients were included in this study if tumor samples from two or more different meningiomas were available.

A total of 7 patients underwent repeated surgery for recurrent meningiomas ( 4 males, 3 females, mean age: 45.4 years at the date of surgery) between 1999 and 2015. Collectively, 22 biopsies were analyzed with FISH (fluorescence-in-situhybridization) for the chromosomal region 17q23.3. In 20/22 (90.1\%) specimens, the tumor samples harboured a significant deletion in the chromosomal region 17q (range: 10 to 63\% of the cells). In 3/3 (100\%) cases, deletion in the $17 q$ chromosomal region was detectable in the primary tumor. In the tumor evolution, there was no steady in- or decrease in the percentage of this deletion.

Conclusion: Deletion in the 17q chromosomal region was present in the patients' primary tumors as well as in late recurrences. Overall, a significant deletion in the $17 \mathrm{q}$ chromosomal region was detected in $90.1 \%$ of the tumors. Thus, the authors assume that deletion in the $17 \mathrm{q}$ chromosomal region displays rather an early event in meningioma progression. Accordingly, deletion in the $17 \mathrm{q}$ chromosomal region might clinically serve as a potential early marker for malignancy and a higher risk for recurrence in meningiomas.

Keywords: Recurrent meningioma, Chromosome 17, Genetic alterations

\footnotetext{
* Correspondence: ralf.ketter@uks.eu

Department of Neurosurgery, Saarland University Hospital, Kirrberger Straße,
} 66421 Homburg/Saar, Germany

(c) The Author(s). 2019 Open Access This article is distributed under the terms of the Creative Commons Attribution 4.0 International License (http://creativecommons.org/licenses/by/4.0/), which permits unrestricted use, distribution, and reproduction in any medium, provided you give appropriate credit to the original author(s) and the source, provide a link to the Creative Commons license, and indicate if changes were made. The Creative Commons Public Domain Dedication waiver (http://creativecommons.org/publicdomain/zero/1.0/) applies to the data made available in this article, unless otherwise stated. 


\section{Introduction}

Meningiomas are the most frequent intracranial tumors. They account for about $30 \%$ of all brain tumors with an annual incidence rate of 10.5 cases per 100,000 females and 4.8 cases per 100,000 males [1]. They are among the cytogenetically best studied tumors and typically reveal a normal karyotype or losses - mostly monosomy and only rarely deletions - of chromosome 22. It is well known that monosomy 22 is not associated with tumor progression or recurrence in meningiomas. However, secondary losses of other chromosomes are accompanied by a more aggressive tumor behavior (rapid tumor growth, infiltrative character) and/or a higher risk of recurrence. Increasing hypodiploidy and complex aberrations are known to induce higher tumor malignancy in meningiomas. Relevant autosomes encompass chromosomes 1, 6, 9, 10, 14, 18 and 19 [2, 3]. As described in the literature, meningiomas with a complex karyotype show higher rates of malignancy [4-6]. Beyond that, epigenetic markers are described to influence meningioma progression and recurrence [7]. However, the current WHO classification of meningiomas subdivides the tumors in three groups based on histological criteria alone [1]. Malignancy and the risk for tumor recurrence increase with higher WHO grading. Recurrence rates after resection Simpson grade I or II are 3-7\% for benign, $34.6-38 \%$ for atypical and $72.7-78 \%$ for anaplastic meningiomas $[8,9]$. Valuable histological predictors for meningioma recurrence in benign meningiomas have not yet been identified. To date, loss of the chromosomal region $1 \mathrm{p}$ and mutations in SMO, AKT1 and the TERT promoter are independent (cyto-)genetic predictors for meningioma recurrence [3, 7, 10-12].

While aberrations of the chromosomes 1, 10 and 22 and their influence on meningioma recurrence are well studied, aberrations of chromosome 17 are seldomly described.

There are several tumor suppressor genes on chromosome 17 that have been investigated concerning their influence on meningioma progression (Table 1).

Deletions of TP53 are associated with higher malignancy and a higher risk for recurrence [13]. A relationship between alterations of $B R C A 1$ and $B R C A 2$ and tumor progression in meningiomas could not be proved [14].

Table 1 Candidate genes on chromosome 17

\begin{tabular}{lll}
\hline Gen & Lokus & Funktion \\
\hline TP53(p53) & $17 p 13.1$ & Apoptosis, cell cycle control \\
NF1 & $17 q 11.2$ & Ras signaling, cell cycle control \\
RPS6KB1 & $17 q 23.2$ & Proliferation control \\
BRCA1 & $17 q 21.31$ & DNA repair \\
NM23 & $17 q 21.33$ & Nucleosiddiphosphatkinase \\
\hline
\end{tabular}

NM23 is a candidate gene on the $17 \mathrm{q}$ chromosomal region. Increased expression of NM23 is associated with a better prognosis in colorectal cancer and breast cancer, whereas deletion in the $17 q$ chromosomal region predicts occurrence of liver metastasis in colorectal cancer [15].

Furthermore, meningiomas with gains of the $17 q$ chromosomal region are also known to show a more aggressive behavior and a higher recurrence rate than meningiomas without this aberration. If there is an increased expression of the oncogene $E R B B 2$ on the chromosomal region $17 q$, a shorter progression free survival in colorectal cancer is described $[15,16]$.

Using comperative genomic hybridization, losses on chromosomes 1p, 6q, 9p, 10,14q, 18q and 22q as well as gains of genetic material at $1 p, 9 p, 12 q, 15 q 20 q$ and $17 p$ were found in anaplastic meningiomas [17-19]. The increase in copy numbers on the long arm of chromosome 17 , determined by $\mathrm{CGH}$ in $42 \%$ of the anaplastic meningiomas investigated by Büschges et al. was substantial, suggesting amplification of DNA sequences.

Also, further studies using non-radioactive in situ hybridization revealed trisomy 17 in meningiomas combined with intratumorous heterogeneity in these cases [20, 21].

While amplification of regions on chromosome 17 is well described in the progression and recurrence of meningioma, there knowledge about the loss of one chromosome 17 in meningiomas and its meaning concerning recurrences and progression in meningiomas is sparse. Here, the authors seek to elucidate the role of deletion in the $17 \mathrm{q}$ chromosomal region in recurrent meningiomas.

\section{Material and methods \\ Patient population}

The authors retrospectively reviewed all patients that underwent repeated surgery for recurrent meningiomas between 1999 and 2015 at the Department of Neurosurgery of the Saarland University Hospital. Patients were included in this study if tumor samples from two or more different meningiomas were available. (Table 2).

\section{Fluorescence in-situ hybridization analysis}

The tumor samples were examined with direct and indirect fluorescence in-situ hybridization (FISH) for the chromosomal regions 17q, 10cen, $1 \mathrm{p}$ and $22 \mathrm{q}$ (Fig. 1). At least two different meningiomas of each patient were examined to evaluate the clonal cytogenetic evolution of recurrent meningiomas. FISH was performed on freshly removed tumor specimens, dapped on silanized microscope slides. FISH after a modified protocol of Pinkel et al. for the chromosomes $1 \mathrm{p}, 10,17 \mathrm{q}$ and $22 \mathrm{q}$ was performed [22]. For chromosome 10, DNA-probes established by our laboratory were used. For the chromosomes 1 and 22, DNA probes by MetaSystems were used. For chromosome 
Table 2 Patient population

\begin{tabular}{|c|c|c|c|c|}
\hline Patient & $\begin{array}{l}\text { Age at first surgery } \\
\text { (years) }\end{array}$ & $\begin{array}{l}\text { Date of surgery } \\
(\mathrm{m} / \mathrm{y})\end{array}$ & Tumor & $\begin{array}{l}\text { Tumor } \\
\text { status }\end{array}$ \\
\hline \multirow[t]{4}{*}{1} & 46 & $08 / 2002$ & 1.1 & $\begin{array}{l}\text { Recurrence } \\
1\end{array}$ \\
\hline & & $10 / 2004$ & 1.2 & $\begin{array}{l}\text { Recurrence } \\
2\end{array}$ \\
\hline & & 09/2005 & 1.3 & $\begin{array}{l}\text { Recurrence } \\
3\end{array}$ \\
\hline & & 08/2006 & 1.4 & $\begin{array}{l}\text { Recurrence } \\
4\end{array}$ \\
\hline \multirow[t]{3}{*}{2} & 38 & $11 / 2009$ & 2.1 & $\begin{array}{l}\text { Primary } \\
\text { tumor }\end{array}$ \\
\hline & & $03 / 2012$ & 2.2 & $\begin{array}{l}\text { Recurrence } \\
1\end{array}$ \\
\hline & & $10 / 2015$ & 2.3 & $\begin{array}{l}\text { Recurrence } \\
5\end{array}$ \\
\hline \multirow[t]{3}{*}{3} & 34 & $02 / 2002$ & 3.1 & $\begin{array}{l}\text { Recurrence } \\
2\end{array}$ \\
\hline & & $08 / 2003$ & 3.2 & $\begin{array}{l}\text { Recurrence } \\
3\end{array}$ \\
\hline & & $02 / 2005$ & 3.3 & $\begin{array}{l}\text { Recurrence } \\
4\end{array}$ \\
\hline \multirow[t]{4}{*}{4} & 45 & 20/2012 & 4.1 & $\begin{array}{l}\text { Recurrence } \\
5\end{array}$ \\
\hline & & $07 / 2013$ & 4.2 & $\begin{array}{l}\text { Recurrence } \\
6\end{array}$ \\
\hline & & $04 / 2014$ & 4.3 & $\begin{array}{l}\text { Recurrence } \\
7\end{array}$ \\
\hline & & $03 / 2015$ & 4.4 & $\begin{array}{l}\text { Recurrence } \\
8\end{array}$ \\
\hline \multirow[t]{2}{*}{5} & 32 & 07/1999 & 5.1 & $\begin{array}{l}\text { Primary } \\
\text { tumor }\end{array}$ \\
\hline & & $01 / 2002$ & 5.2 & $\begin{array}{l}\text { Recurrence } \\
2\end{array}$ \\
\hline \multirow[t]{3}{*}{6} & 61 & 03/2001 & 6.1 & $\begin{array}{l}\text { Primary } \\
\text { tumor }\end{array}$ \\
\hline & & $08 / 2001$ & 6.2 & $\begin{array}{l}\text { Recurrence } \\
1\end{array}$ \\
\hline & & $10 / 2001$ & 6.3 & $\begin{array}{l}\text { Recurrence } \\
2\end{array}$ \\
\hline \multirow[t]{2}{*}{7} & 62 & $11 / 2001$ & 7.1 & $\begin{array}{l}\text { Recurrence } \\
3\end{array}$ \\
\hline & & $10 / 2013$ & 7.2 & $\begin{array}{l}\text { Recurrence } \\
4\end{array}$ \\
\hline
\end{tabular}

17, a DNA probe by Abott Laboratories was used. For detection of aberrations of chromosome 10 and the $17 \mathrm{q}$ chromosomal region, indirect FISH was performed. Aberrations of the chromosomal regions $1 p$ and $22 q$ were detected by direct FISH.

Samples were analyzed with an Olympus BX43 fluorescence microscope. At least 200 nuclei of each tumor were analyzed according to the criteria of Hopman et al. [23]. A cut-off value of $10 \%$ for alterations of all chromosomes was determined.

\section{Chromosomal aberration patterns}

Based on the FISH results, chromosomal aberration patterns for each tumor were established. Aberration patterns with chromosomal aberrations in three or more chromosomes within a given tumor were rated as complex patterns.

\section{Results}

FISH analysis was performed on 22 meningioma biopsies (1 WHO I-, 13 WHO II-, 8 WHO III-Tumors) out of 7 patients ( 4 males, 3 females). Among the 22 biopsies, there were three biopsies of primary tumors and 19 biopsies of recurrences The mean patient age at the first date of surgery was 45.4 years (Table 2 ).

\section{FISH results for chromosome $1 p, 10,17$ and $22 q$}

FISH for the chromosomal regions $1 \mathrm{p}, 10 \mathrm{cen}, 17 \mathrm{q}$ and $22 \mathrm{q}$ was performed on 22 meningioma tissue samples from 7 patients. To evaluate the influence of deletions in the $17 \mathrm{q}$ chromosomal region on tumor progression in meningiomas in the course of time, at least two different meningiomas from each patient were analyzed. In 20/22 (90.1\%) cases, tumor samples showed a significant deletion in the $17 \mathrm{q}$ chromosomal region (Figs. 2- $d$ ). Additional aberrations appeared in the following frequencies: deletion of the chromosomal region 1p in 20/ 21 tumors $(47.6 \%)$, deletoin of chromosome 10cen in 6/ 21 tumors (28.6\%), deletion of the chromosomal region $22 \mathrm{q}$ in $17 / 21$ tumors $(80.9 \%)$ and gain of the chromosomal region $17 \mathrm{q}$ in $8 / 21$ tumors $(38.1 \%)$. Table 3 depicts the FISH results as an aberration pattern for each tumor (Table 3).

\section{Chromosomal aberration patterns}

A subdivision of the tumors into aberration groups was conducted to separate simple from complex aberration patterns (Fig. 3). In our study we detected ten different aberration groups (A1 -A10). Aberration patterns with chromosomal aberrations in three or more chromosomes within a given tumor were rated as complex patterns. The complex aberration patterns of the groups A1, A2 and A3 in which additional loss of one short arm of one chromosome 1 was detectable, accounted for $47.6 \%$ of all tumors in this study (Fig. 4).

Time course of deletions in the $17 \mathrm{q}$ chromosomal region Deletions in the $17 \mathrm{q}$ chromosomal region were present also in the patients' early tumor specimens. In 3 cases, specimens of the primary tumor were available. In $3 / 3$ cases $(100 \%)$, deletions in the $17 \mathrm{q}$ chromosomal region were detected in the primary tumor (patients 2, 5 and 6). To evaluate a time-course of deletions of chromosome $17 \mathrm{q}$, at least two meningiomas of each patient were examined. No overall increase or decrease was 

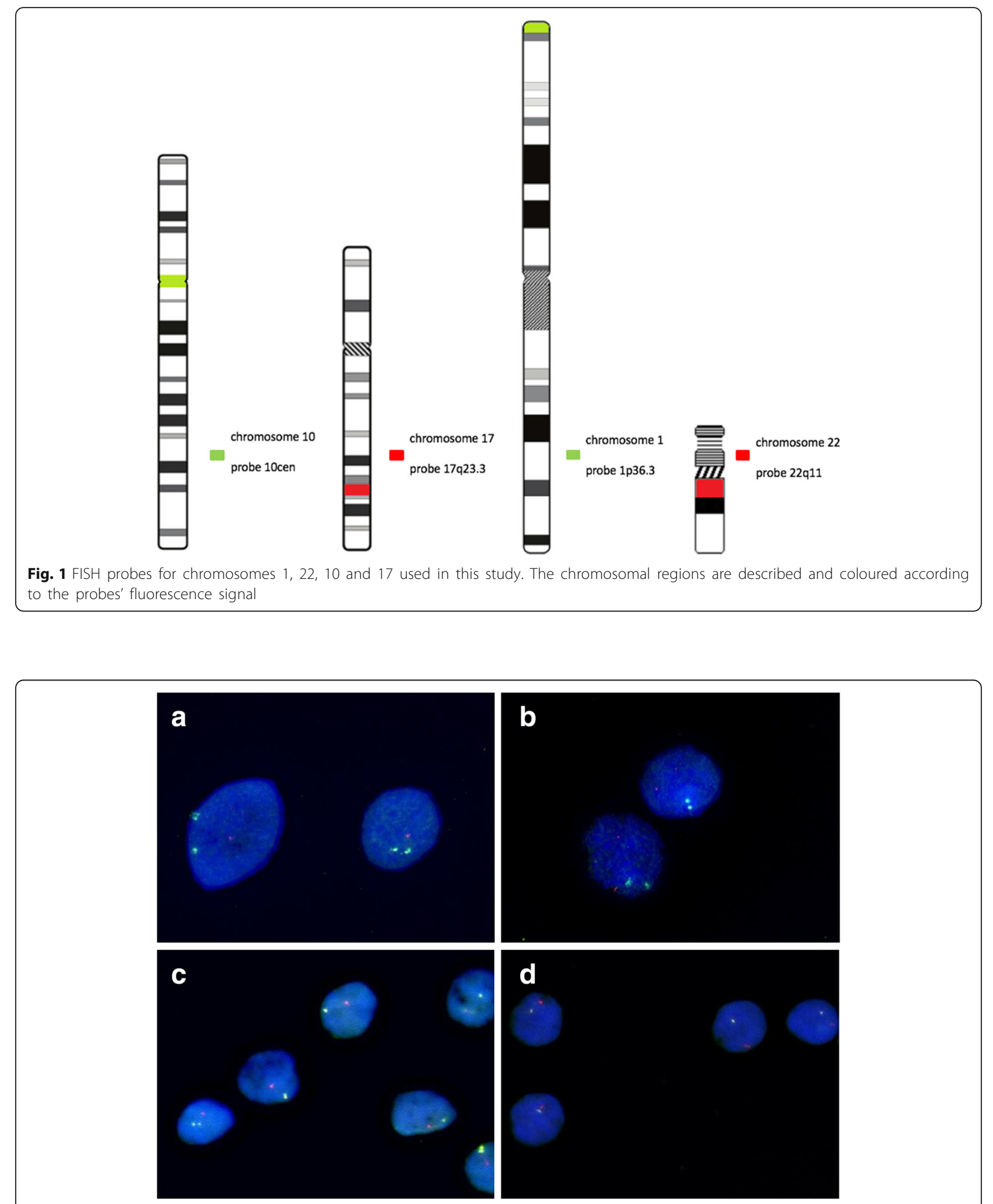

Fig. 2 a Tumor 6.2, FISH for chromosomes 10 and 17q, deletion of chromosome 17q; green: chromosome 10, red: chromosome 17q. b Tumor 6.2, FISH for chromosomes 10 and 17q, deletion of chromosome 17q; green: chromosome 10, red: chromosome 17q. c Tumor 1.1, FISH for chromosomes $1 p$ and 22q, loss of chromosomes $1 p$ and 22q; green: chromosome 1p, red: chromosome 22q. d Tumor 1.1, FISH for chromosomes $1 p$ and 22q, loss of chromosomes $1 p$ and 22q; green: chromosome 1p, red: chromosome 22q 
Table 3 Aberration-patterns for chromosomal regions 10cen, 17q, $1 \mathrm{p}$ and 22q. 1: deletion detectable, 0 : no deletion detectable; $(P)$ = primary tumor, $(R)=$ recurrence

\begin{tabular}{|c|c|c|c|c|c|c|c|}
\hline Patient & Tumor & WHO & $-17 q$ & $-22 q$ & $-1 p$ & -10cen & $+17 q$ \\
\hline \multirow[t]{4}{*}{ Patient 1} & $1.1(\mathrm{R})$ & 2 & 1 & 1 & 1 & 0 & 0 \\
\hline & $1.2(\mathrm{R})$ & 2 & 1 & 1 & 1 & 0 & 0 \\
\hline & $1.3(\mathrm{R})$ & 2 & 1 & 1 & 1 & 0 & 0 \\
\hline & $1.4(\mathrm{R})$ & 2 & 1 & 0 & 0 & 0 & 1 \\
\hline \multirow[t]{3}{*}{ Patient 2} & $2.1(P)$ & 3 & 1 & 1 & 1 & 0 & 1 \\
\hline & $2.2(\mathrm{R})$ & 3 & 1 & 1 & 0 & 1 & 0 \\
\hline & $2.3(\mathrm{R})$ & 3 & 1 & 1 & 0 & 0 & 0 \\
\hline \multirow[t]{3}{*}{ Patient 3} & $3.1(\mathrm{R})$ & 2 & 1 & 0 & 0 & 0 & 0 \\
\hline & $3.2(\mathrm{R})$ & 2 & 1 & 0 & 0 & 0 & 1 \\
\hline & $3.3(\mathrm{R})$ & 2 & 1 & 1 & 0 & 1 & 0 \\
\hline \multirow[t]{4}{*}{ Patient 4} & $4.1(\mathrm{R})$ & 2 & 1 & 1 & 1 & 1 & 0 \\
\hline & $4.2(\mathrm{R})$ & 2 & 1 & 1 & 1 & 1 & 0 \\
\hline & $4.3(\mathrm{R})$ & 2 & 1 & 1 & 1 & 1 & 0 \\
\hline & $4.4(\mathrm{R})$ & 2 & 1 & 0 & 0 & 1 & 0 \\
\hline \multirow[t]{2}{*}{ Patient 5} & $5.1(P)$ & 2 & 1 & 1 & 0 & 0 & 1 \\
\hline & $5.2(\mathrm{R})$ & 2 & 1 & 1 & 0 & 0 & 0 \\
\hline \multirow[t]{3}{*}{ Patient 6} & $6.1(P)$ & 3 & 1 & 1 & 1 & 0 & 1 \\
\hline & $6.2(\mathrm{R})$ & 3 & 1 & 1 & 1 & 0 & 1 \\
\hline & $6.3(\mathrm{R})$ & 3 & 0 & 1 & 0 & 0 & 1 \\
\hline \multirow[t]{2}{*}{ Patient 7} & $7.1(\mathrm{R})$ & 1 & 1 & 1 & 1 & 0 & 0 \\
\hline & $7.2(\mathrm{R})$ & 3 & 1 & 1 & 0 & 0 & 0 \\
\hline \multicolumn{2}{|c|}{ Frequency total } & & $20 / 21$ & $17 / 21$ & $10 / 21$ & $6 / 21$ & $8 / 21$ \\
\hline \multicolumn{2}{|c|}{ Frequency percentage } & & $95.2 \%$ & $80.9 \%$ & $47.6 \%$ & $28.6 \%$ & $38.1 \%$ \\
\hline
\end{tabular}

found in the amount of deletions in the $17 \mathrm{q}$ chromosomal region over time.

\section{Time course of patient 4}

Analysis for patient 4 first started with the 5th recurrence of this patient. CGH of the 7th recurrence displayed loss of chromosome 17. FISH revealed a deletion on 17q23.3 in all of the examined specimens and not only in the 7th recurrence.

\section{FISH vs. CGH/karyotyping}

Deletions in the $17 \mathrm{q}$ chromosomal region were detected by FISH in $20 / 22(90.1 \%)$ samples. Only $1 / 10$ (10\%) CGH and none of the karyotyping results harboured deletions in the 17q chromosomal region. (Table 4).

\section{Discussion}

Meningiomas are the most frequent intracranial tumours. In addition to the common genetic alteratons in NF2 in sporadic meningiomas, a number of other clinically actionable genetic events have been described in meningiomas over the past 10 years. Despite tumor

\begin{tabular}{|c|c|c|}
\hline Group & $\begin{array}{c}\text { Aberration } \\
\text { pattern }\end{array}$ & Color code \\
\hline A1 & $-1 p,-17,-22 q$ & \\
\hline A2 & $-1 p,-17,+17,-22 q$ & \\
\hline A3 & $-1 p,-10,-17,-22 q$ & \\
\hline A4 & $-17,-22 q$ & \\
\hline A5 & $-10,-17,-22 q$ & \\
\hline A6 & $-17,+17$ & \\
\hline A7 & $-10,-17$ & \\
\hline A8 & $-17,+17,-22 q$ & \\
\hline A9 & $+17,-22 q$ & \\
\hline A10 & -17 & \\
\hline
\end{tabular}

Fig. 3 In our study we detected ten different aberration-groups (A1 - A10). We defined the groups A1, A2 and $A 3$ as the groups with the highest mode of aberrations, whereas group A10 represents the group with the lowest complexity of aberrations detected in our study. The tumors for each group are listed according to their specific aberration pattern

resection Simpson grade I and histopathological grading as WHO grade I, some meningiomas recur. To date, loss of the chromosomal region $1 \mathrm{p}$ and mutations in $S M O$, $A K T 1$ and the TERT-promoter are known as independent predictors for meningioma recurrence [3, 7, 10-12]. Further genetic and epigenetic markers are described to influence meningioma progression. Meningiomas with mutations of the TERT-promoter are associated with shorter time to progression and a higher risk of 


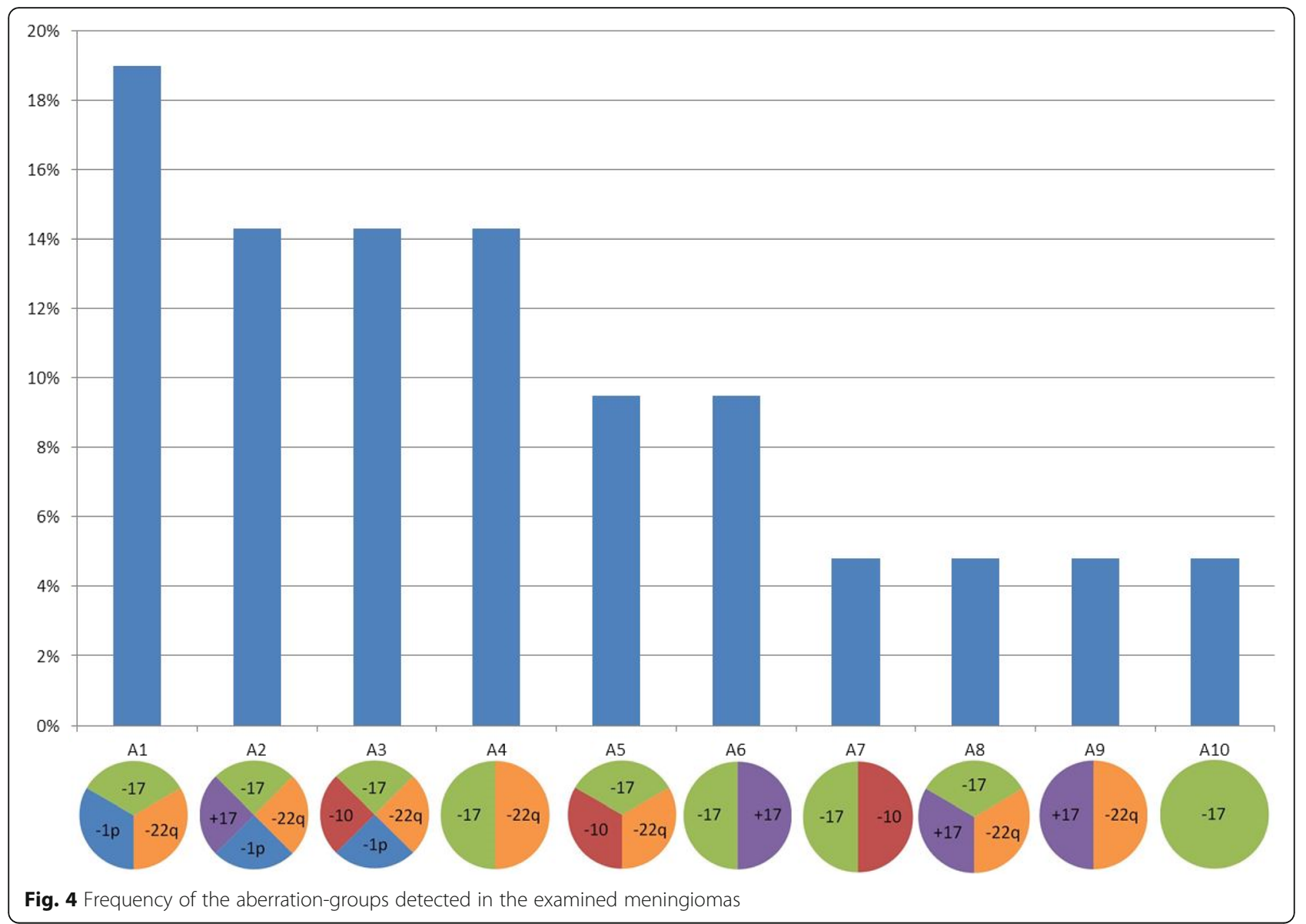

recurrence [12]. The influence of deletions in the $17 q$ chromosomal region on meningioma recurrence ist not described in the literature yet. Here, the authors seeked to further elucidate the role of deletions in the $17 \mathrm{q}$ chromosomal region in recurrent meningiomas.

Table 4 Comparison of the results from conventional karyotyping and FISH for chromosome $17 \mathrm{q}$

\begin{tabular}{llll}
\hline Tumor & Karyotype & \multicolumn{2}{l}{ FISH 17 for chromosome 17q } \\
\cline { 3 - 4 } & & Aberration & Frequency \\
\hline 1.4 & der(1)t(1;9)(p12;q21) & $-17 q$ & $38.5 \%$ \\
3.1 & Normal karyotype & $-17 q$ & $35.5 \%$ \\
3.2 & Normal karyotype & $-17 q$ & $18.5 \%$ \\
4.1 & CGH: $-1 p,-10,-22$ & $-17 q$ & $68.5 \%$ \\
4.2 & CGH: $-1 p,-10,-22$ & $-17 q$ & $37.5 \%$ \\
4.3 & CGH: $-1 p,-10,-17,-22$ & $-17 q$ & $31.5 \%$ \\
5.1 & $-22 q$ & $-17 q$ & $44 \%$ \\
5.2 & -22 & $-17 q$ & $57 \%$ \\
6.1 & $-1 p,-22$ & $-17 q$ & $11 \%$ \\
6.2 & $-1 p,-22$ & $-17 q$ & $18 \%$ \\
\hline
\end{tabular}

Role of chromosome 17 in meningiomas in the literature Until today, little is known about loss of chromosome 17 in meningiomas while gain and aberrations of chromosome 17 in meningiomas have previously been described by several authors. Gain of chromosome 17 is associated with a more aggressive behavior of the tumors $[18,19]$, but the cited studies did either not examine more than one tumor of the same patient, or they did not reveal losses of chromosome 17 with the chosen method. In particular, small mosaics and intratumoral heterogeneity remain undetectable by CGH (Comparative genomic hybridization) or other quantitative methods on tumor samples.

Arnoldus et al. could detect loss of chromosome 17 by FISH (Fluorescence in situ hybridization) in 1 of 30 meningiomas. The examined tumor was a recurrent meningioma [20]. Yakut et al. could detect a deletion of TP53, which is located on chromosome 17p, by FISH in 3 of 34 meningiomas. The three patients developed recurrence during the follow up period [13]. LOH (Loss of heterozygosity) of the chromosomal region 17p, on which TP53 resides, has been described by several authors. However, no statement is made about deletion of the chromosomal region 17q. Lamszus et al. performed $\mathrm{LOH}$ analysis on five 
patients with recurrent meningiomas, but did not examine chromosome 17 [21]. Conventional karyotyping by Lopez-Gines et al. on recurrent meningiomas from nine patients did not reveal loss of chromosome 17 [5].

\section{FISH vs. CGH/karyotyping}

FISH is known to be more sensitive than CGH and karyotyping after cell culture in detecting mosaic chromosomal aberrations [22, 23]. By comparing FISH and CGH/karyotyping results of the tumors in 10/22 cases we could confirm the results of our former study and Nordkamp et al. $[22,23]$.

\section{Chromosomal aberration patterns}

Complex aberration patterns in meningiomas are associated with a more aggressive behavior and a higher risk for recurrence [4-6]. The complex aberration patterns A2 and $\mathrm{A} 3$ were the most frequent patterns in our cohort and were rated as complex. The frequency of recurrence of the tumors in this study and the amount of complex aberration patterns can confirm the results that are described in the literature [4-6].

\section{Is deletion of chromosome $17 q$ a late event in meningioma progression?}

Since loss of chromosome 17 in our patients was first detected in the 7 th recurrence of patient 4 , we assumed that loss of chromosome 17 could be a late event in meningioma progression. However, despite our presumption of being a late event in meningioma progression, deletions in the $17 \mathrm{q}$ chromosomal region were also present in the patient's primary tumors and early recurrences. No overall increase or decrease in the percentage of deletions in the 17q chromosomal region was detectable. Therefore, deletions in the $17 \mathrm{q}$ chromosomal region seem to be an early event in meningioma tumor progression associated with a higher risk for recurrence even in the absence of morphological signs of malignancy.

As it is well known that meningiomas mostly show complete monosomy of chromosome 22 rather than partial chromosomal losses like the loss of the short arm of chromosome 1, the authors assume that deletions in the $17 \mathrm{q}$ chromosomal region display a loss of the long arm of chromosome 17, or even complete monosomy of chromosome 17 .

\section{Conclusion}

Deletions in the $17 \mathrm{q}$ chromosomal region may represent a potential early marker for meningioma progression and recurrence when detected in a primary meningioma. Further prospective studies including primary tumors of all WHO grades and higher numbers of specimens should be performed to determine the value of loss of chromosome 17 in meningiomas.

The combined approach of histology and genetic patterns in meningiomas represents the future of meningioma diagnostics, providing a possibility to stratify the risk of recurrence and the aggressive behavior of a given meningioma.

\section{Acknowledgments}

The authors want to thank S. Welsch and S. Hoffmann for their technical support on the cytogenetic analysis. The authors thank Prof. Dr. W. Henn and Prof. Dr. K. D. Zang for proofreading the manuscript.

\section{Funding}

No funding was obtained for the preparation of this article.

Availability of data and materials

Data sharing is not applicable to this article as all data is provided in the article.

\section{Authors' contributions}

$\mathrm{SH}$ did the cytogenetic testing, wrote, reviewed and revised the manuscript. SU gave support on the interpretation of the cytogenetic data, reviewed and revised the manuscript. JO collected the tumor samples, reviewed and revised the manuscript and provided overall supervision. RK collected the tumor samples and clinical data, reviewed and revised the manuscript and provided overall supervision. All authors read and approved the final manuscript.

\section{Ethics approval and consent to participate}

The study has been approved by the ethical committee Saarland, reference number 178/07.

Patients have given written informed consent to the genetic analysis of the tumors.

\section{Consent for publication}

Written consent was obtained from the patients for the publication of the data.

\section{Competing interests}

The authors declare that they have no competing interests.

\section{Publisher's Note}

Springer Nature remains neutral with regard to jurisdictional claims in published maps and institutional affiliations.

Received: 18 December 2018 Accepted: 15 May 2019

Published online: 24 May 2019

References

1. Louis DN, Ohgaki H, Wiestler OD, Cavanee WK. WHO classification of Tumours of the central nervous system revised 4th edition. Lyon: International Agency for Research on Cancer (IARC); 2016.

2. Zang KD. Meningioma: a cytogenetic model of a complex benign human tumor, including data on 394 karyotyped cases. Cytogenet Cell Genet. 2001; 93:207-20.

3. Ketter R, Urbschat S, Henn W, Feiden W, Beerenwinkel N, Lengauer T, et al. Application of oncogenetic trees mixtures as a biostatistical model of the clonal cytogenetic evolution of meningiomas. Int J Cancer. 2007;121:1473-80

4. Ketter R, Kim YJ, Storck S, Rahnenführer J, Romeike BFM, Steudel WI, et al. Hyperdiploidy defines a distinct cytogenetic entity of meningiomas. J Neuro Oncol. 2007:83:213-21.

5. Lopez-Gines C, Cerda-Nicolas M, Barcia-Salorio JL, Llombart-Bosch A. Cytogenetical findings of recurrent meningiomas-a study of 10 tumors. Cancer Genet Cytogenet. 1995;85:113-7.

6. Henriques Domingues P, Sousa P, Otero Á, Gonçalves JM, Ruiz L, De Oliveira $C$, et al. Proposal for a new risk stratification classification for meningioma 
based on patient age, WHO tumor grade, size, localization, and karyotype. Neuro Oncology. 2014;16:735-47.

7. Sahm F, Schrimpf D, Stichel D, Jones DTW, Hielscher T, Schefzyk S, et al. DNA methylation-based classification and grading system for meningioma: a multicentre, retrospective analysis. Lancet Oncol. 2017;18:682-94.

8. Jääskeläinen J, Haltia M, Servo A. Atypical and anaplastic meningiomas: radiology, surgery, radiotherapy, and outcome. Surg Neurol. 1986;25:233-42.

9. Maier H, Ofner D, Hittmair A, Kitz K, Budka H. Classic, atypical, and anaplastic meningioma: three histopathological subtypes of clinical relevance. J Neurosurg. 1992;77:616-23.

10. Linsler S, Kraemer D, Driess C, Oertel J, Kammers K, Rahnenführer J, et al. Molecular biological determinations of meningioma progression and recurrence. PLoS One. 2014;9:e94987.

11. Preusser M, Brastianos PK, Mawrin C. Advances in meningioma genetics: novel therapeutic opportunities. Nat Rev Neurol. 2018;14:106-15.

12. Sahm F, Schrimpf D, Olar A, Koelsche C, Reuss D, Bissel J, et al. TERT promoter mutations and risk of recurrence in meningioma. J Natl Cancer Inst. 2016;108:1-4.

13. Yakut T, Bekar A, Doygun M, Acar H, Egeli U, Ogul E. Evaluation of relationship between chromosome 22 and p53 gene alterations and the subtype of meningiomas by the interphase-FISH technique. Teratog Carcinog Mutagen. 2002;22:217-25.

14. Kirsch M, Zhu JJ, Black PM. Analysis of the BRCA1 and BRCA2 genes in sporadic meningiomas. Genes Chromosom Cancer. 1997;20:53-9.

15. Kawai M, Komiyama H, Hosoya M, Okubo H, Fujii T. Impact of chromosome 17q deletion in the primary lesion of colorectal cancer on liver metastasis. Oncol Lett. 2016;12:4773.

16. Sefrioui $D$, Vermeulin $T$, Blanchard F, Chapusot $C$, Beaussire L, ArmengolDebeir $L$, et al. Copy number variations in DCC/ 18q and ERBB2/17q are associated with disease-free survival in microsatellite stable colon cancer. Int J Cancer. 2017;140:1653-61.

17. Büschges $R$, Ichimura $K$, Weber RG, Reifenberger $G$, Collins VP. Allelic gain and amplification on the long arm of chromosome 17 in anaplastic meningiomas. Brain Pathol. 2002;12:145-53.

18. Weber RG, Boström J, Wolter M, Baudis M, Collins VP, Reifenberger G, et al. In situ hybridization as a tool to study numerical chromosome aberrations in solid bladder tumors. Histochemistry. 1988:89:307-16.

19. Hartmann C, Boström J, Simon M. Diagnostic and molecular pathology of meningiomas. Expert Rev Neurother. 2006;6:1671-83.

20. Arnoldus EP, Wolters LB, Voormolen JH, Van Duinen SG, Raap AK, Van der Ploeg M, et al. Interphase cytogenetics: a new tool for the study of genetic changes in brain tumors. J Neurosurg. 1992;76:997-1003.

21. Lamszus K, Kluwe L, Matschke J, Meissner H, Laas R, Westphal M. Allelic losses at 1p, 9q, 10q, 14q, and 22q in the progression of aggressive Meningiomas and undifferentiated meningeal sarcomas. Cancer Genet Cytogenet. 1999:110:103-10.

22. Lerner C, Ketter R, Linsler S, Henn W, Oertel J, Urbschat S. Establishment of a molecular cytogenetic analysis for native tumor tissue of meningiomassuitable for clinical application. Mol Cytogenet. 2014;7.

23. Olde Nordkamp L, Mellink C, van der Schoot E, van den Berg $H$. Karyotyping, FISH, and PCR in acute lymphoblastic leukemia: competing or complementary diagnostics? J Pediatr Hematol Oncol. 2009;31:930-5.

Ready to submit your research? Choose BMC and benefit from:

- fast, convenient online submission

- thorough peer review by experienced researchers in your field

- rapid publication on acceptance

- support for research data, including large and complex data types

- gold Open Access which fosters wider collaboration and increased citations

- maximum visibility for your research: over $100 \mathrm{M}$ website views per year

At $\mathrm{BMC}$, research is always in progress.

Learn more biomedcentral.com/submissions 